EPJ Web of Conferences 92,02106 (2015)

DOI: $10.1051 /$ epjconf/ 20159202106

C Owned by the authors, published by EDP Sciences, 2015

\title{
Thermodynamic properties of real gases and BWR equation of state
}

\author{
Magda Vestfálová ${ }^{1, a}$ \\ ${ }^{1}$ KEZ, TU Liberec, Studentská 1402/2, 46117 Liberec 1, Czech Republic
}

\begin{abstract}
The fundamental base for the calculation of the thermodynamic properties of materials is thermal equation of state and dependence of some of the basic specific heat capacities on temperature. The dependence of the specific thermal capacity on the second independent variable (for example on the volume) it is already possible to deduce from the thermal equation of state. The aim of this paper is to assess the compliance values of specific heat capacity which was calculated using the BWR thermal equation of the state and experimentally obtained known values of specific heat capacity for the substance, whose characteristics are available in a wide range of state space.
\end{abstract}

\section{Thermal equation of state BWR}

State variables $p, T$ and $v$, resp. $\rho$ are bound together by a thermal equation of state. It is not possible to make a universal type of state equation, which provides for different substance under different conditions computational materials with sufficient accuracy. In 1940 Manson Benedict, G. B. Webb and L. C. Rubin constructed so called original Benedict - Webb - Rubin thermal equation of state (hereinafter BWR) [1]

$p=r T \rho+r T \rho^{2} B_{0}+r T \rho^{3} b-A_{0} \rho^{2}-a \rho^{3}+$

$+a \alpha \rho^{6}-\frac{\rho^{2} C_{0}}{T^{2}}+\frac{c \rho^{3}}{T^{2}}\left(1+\gamma \rho^{2}\right) e^{-\gamma \rho^{2}}$.

Equation has some physical basic in the state behavior of gases. It contains an addition to the specific constant $r$ still eight parameters: $A_{0}, B_{0}, C_{0}, a, b, c, \alpha, \gamma$, that characterize the individual properties of the gas. They must be determined from experimental dates by regression. So, as well as other multi-parameter equations, BWR equation can be only used to description of properties of substances for which there is sufficient amount of experimental data in wide range of pressures and temperatures.

At first BWR equation was suggested for calculation of behavior of hydrocarbons. For these substances values obtained from BWR equation are very close to the experimental date [2]. Parameters of BWR equation for hydrocarbons are presented for example in work [3] too. In 1973 was made a modification of the Benedict-WebbRubin equation of state by Starling [4]

\footnotetext{
${ }^{\mathrm{a}}$ correspondence author: magda.vestfalova@tul.cz
}

$$
\begin{aligned}
& p=r T \rho+r T \rho^{2} B_{0}+r T \rho^{3} b-A_{0} \rho^{2}- \\
& -a \rho^{3}+a \alpha \rho^{6}+\frac{\alpha d \rho^{6}}{T}-\frac{\rho^{2} C_{0}}{T^{2}}+ \\
& +\frac{\rho^{2} D_{0}}{T^{3}}+\frac{\rho^{2} E_{0}}{T^{4}}+\frac{c \rho^{3}}{T^{2}}\left(1+\gamma \rho^{2}\right) e^{-\gamma \rho^{2}} .
\end{aligned}
$$

Values of the various parameters for 15 substances can be found in work [4].

Another modification of the Benedict-Webb-Rubin equation of state was made in 1987 by Jacobsen and Stewart [5], it is noted as mBWR

$$
p=\sum_{n=1}^{9} a_{n} \rho^{n}+\sum_{n=10}^{15} a_{n} \rho^{2 n-17} e^{-\gamma \rho^{2}} .
$$

The mBWR equation subsequently evolved into a 32 term version with numerical parameters determined by fitting the equation to empirical data for a reference fluid [6].

The area of use of BWR equation of state is clearly much broader than in the case of the state equation of ideal gas. This equation of state gives satisfactory results to describe the behavior of hydrocarbons. The literature indicates accuracy from $0.1 \%$ to $0.2 \%$ for the reduced density to $\rho_{r}=\frac{\rho}{\rho_{C R}}=1$ and accuracy between $0.3 \%$ and $0.5 \%$ for the reduced density to $\rho_{r}=2$. BWR is an equation of the physical type.

Let's show the use of thermal equation of state for example $\mathrm{H}_{2} \mathrm{O}$. Original BWR equation of state is not suitable for description the properties of this substance, but we have completely mapped out its properties, so it make it suitable for verification of computational relationship.

In $p-v$ diagram for $\mathrm{H}_{2} \mathrm{O}$ (Figure 1) there are plotted the real isotherms (top to bottom): $1000^{\circ} \mathrm{C}, 500^{\circ} \mathrm{C}$, 
$373.946^{\circ} \mathrm{C}$ (it is critical isotherm), $180^{\circ} \mathrm{C}$ and $100^{\circ} \mathrm{C}$. They are computed due to BWR equation of state. Square points always show the actual course of the isotherm [7]. The diagram also plots limit curve.

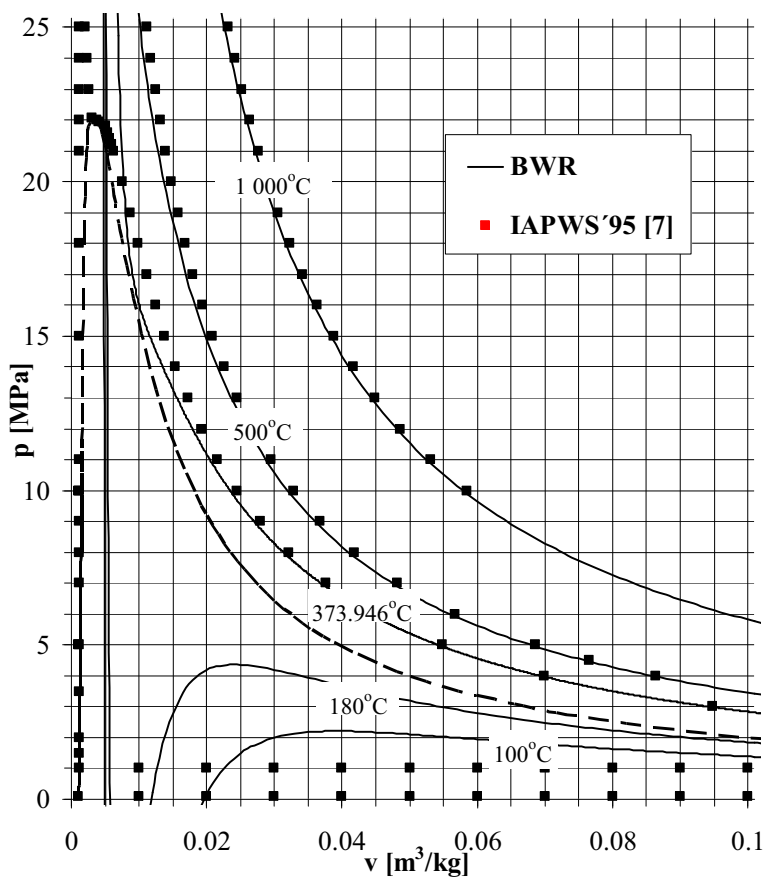

Figure 1. Comparison of isotherms of real substance according BWR equation and according IAPWS'95 data (from below upwards: $100^{\circ} \mathrm{C}, 180^{\circ} \mathrm{C}, 373.946^{\circ} \mathrm{C}$ - critical point, $500^{\circ} \mathrm{C}$, $\left.1000^{\circ} \mathrm{C}\right)$.

We can see that the BWR equation gives very nice results in greater distance from the right marginal curve. In heterogeneous areas (below the limit curve), as expected, there is a local maximum and a local minimum, but in homogeneous areas - fluid (even in areas where $\rho_{r} \approx 1$ ) the results are (compared to results obtained for example for hydrocarbons) totally unrealistic.

Let's look at other properties of real materials.

\section{Specific heat capacity of real substance}

Other variables which are (together with the thermal equation of state) the starting materials for thermal calculations are the basic heat capacities

$c_{V}=\left(\frac{\partial q}{\partial T}\right)_{V}=\left(\frac{\partial u}{\partial T}\right)_{V}=c_{V}(T, v)$

or

$$
c_{p}=\left(\frac{\partial q}{\partial T}\right)_{p}=\left(\frac{\partial h}{\partial T}\right)_{p}=c_{p}(T, p) .
$$

Their total differentials can be written as

$d c_{V}=\left(\frac{\partial c_{V}}{\partial T}\right)_{V} d T+\left(\frac{\partial c_{V}}{\partial v}\right)_{T} d v$ and

$d c_{p}=\left(\frac{\partial c_{p}}{\partial T}\right)_{p} d T+\left(\frac{\partial c_{p}}{\partial p}\right)_{T} d p$.

For values of partial derivatives of the heat capacities on temperature, the theory does not provide any bases. The dependence of heat capacity on temperature thus forms (together with the thermal equation of state) more necessary starting basis for the establishment of relations of computational thermodynamic properties of substances. Usually the dependence of isobaric heat capacity on the temperature of the gas in an idealized state (i.e. for $p \rightarrow 0$ ) is available in the form of

$c_{p}=A+B T+C T^{2}+D T^{3}$.

\section{The dependence of the specific heat capacity on the volume of a substance described BWR equation}

The dependence of isochoric specific heat capacity of the volume can be obtained from the thermal equation of state. We will show this procedure:

By differentiating equation (5) by volume at constant temperature

$\left(\frac{\partial c_{V}}{\partial v}\right)_{T}=\left[\frac{\partial}{\partial v}\left(\frac{\partial u}{\partial T}\right)_{V}\right]_{T}=\left[\frac{\partial}{\partial T}\left(\frac{\partial u}{\partial v}\right)_{T}\right]_{V}$.

Necessary derivative of the internal energy is obtained by differentiating of the Gibbs equation $(d u=T d s-p d v)$ :

$\left(\frac{\partial u}{\partial v}\right)_{T}=T\left(\frac{\partial s}{\partial v}\right)_{T}-p$

and using Maxwell's equation $\left(\frac{\partial s}{\partial v}\right)_{T}=\left(\frac{\partial p}{\partial T}\right)_{V}$

$\left(\frac{\partial u}{\partial v}\right)_{T}=T\left(\frac{\partial p}{\partial T}\right)_{V}-p$

Substituting into equation (9) we obtain

$\left(\frac{\partial c_{V}}{\partial v}\right)_{T}=\left\{\frac{\partial}{\partial T}\left[T\left(\frac{\partial p}{\partial T}\right)_{V}-p\right]\right\}_{V}=T\left(\frac{\partial^{2} p}{\partial T^{2}}\right)_{V}$.

Partial derivatives $\left(\frac{\partial p}{\partial T}\right)_{V}$ and $\left(\frac{\partial^{2} p}{\partial T^{2}}\right)_{V}$ we obtain from the BWR equation (1):

$\left(\frac{\partial p}{\partial T}\right)_{V}=\rho r+\rho^{2} r B_{0}+\rho^{3} r b+$

$+\frac{2 \rho^{2} C_{0}}{T^{3}}-\frac{2 c \rho^{3}}{T^{3}}\left(1+\gamma \rho^{2}\right) e^{-\gamma \rho^{2}}$

and 
$\left(\frac{\partial^{2} p}{\partial T^{2}}\right)_{V}=\left[-\frac{6 \rho^{2} C_{0}}{T^{4}}+\frac{6 c \rho^{3}}{T^{4}}\left(1+\gamma \rho^{2}\right) e^{-\gamma \rho^{2}}\right]$

and so

$$
\begin{aligned}
& \left(\frac{\partial c_{V}}{\partial v}\right)_{T}=T\left(\frac{\partial^{2} p}{\partial T^{2}}\right)_{V}= \\
& =T\left[-\frac{6 \rho^{2} C_{0}}{T^{4}}+\frac{6 c \rho^{3}}{T^{4}}\left(1+\gamma \rho^{2}\right) e^{-\gamma \rho^{2}}\right] .
\end{aligned}
$$

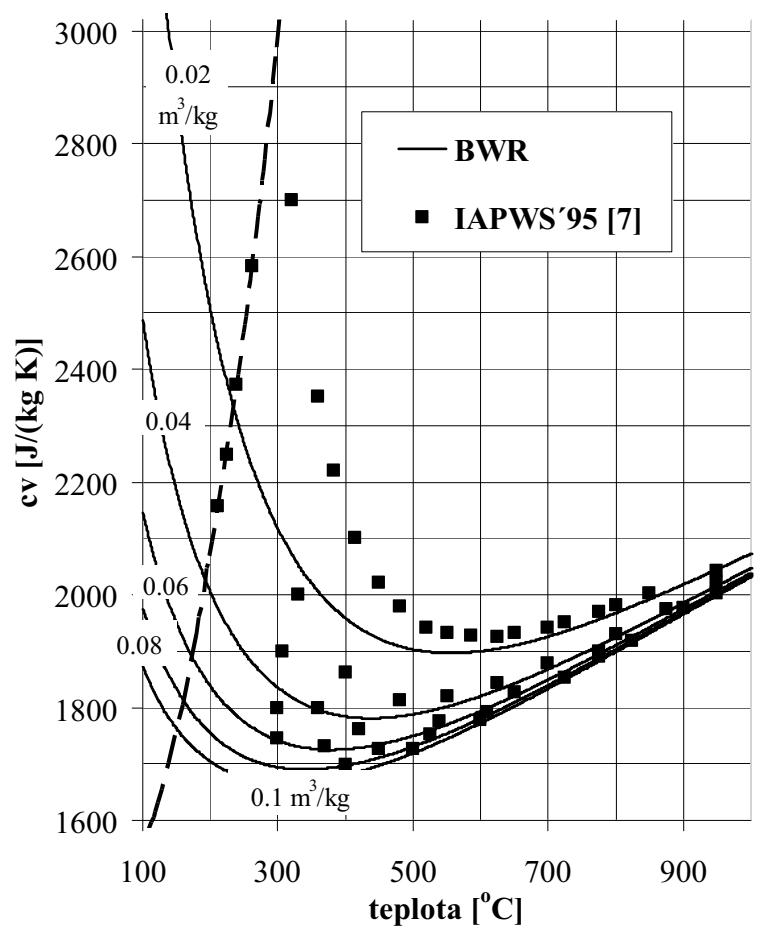

Figure 2. Dependence of the isochoric heat capacity of the temperature and volume for real substance - comparison of results according BWR equation and according IAPWS'95 data (from below upwards): $0.1 \mathrm{~m}^{3} / \mathrm{kg}, 0.08 \mathrm{~m}^{3} / \mathrm{kg}, 0.06 \mathrm{~m}^{3} / \mathrm{kg}, 0.04$ $\mathrm{m}^{3} / \mathrm{kg}, 0.02 \mathrm{~m}^{3} / \mathrm{kg}$ ).

The dependence of isochoric specific heat capacity of the temperature and volume we obtain by integration the relation (15) between "known" and the current state over the volume. The "known" state: the state at $v \rightarrow \infty$, it is the idealized state, for which the specific heat capacity does not depend on volume, but only on the temperature [8]

$$
\begin{aligned}
& c_{V}(T, v)=c_{V}^{i d}(T)+\int_{\infty}^{v}\left(\frac{\partial c_{V}}{\partial v}\right)_{T} d v= \\
& =c_{V}^{i d}(T)+\int_{\infty}^{v} T\left(\frac{\partial^{2} p}{\partial T^{2}}\right)_{V} d v=c_{V}^{i d}(T)+ \\
& +\int_{\infty}^{v}\left[-\frac{6 \rho^{2} C_{0}}{T^{3}}+\frac{6 c \rho^{3}}{T^{3}}\left(1+\gamma \rho^{2}\right) e^{-\gamma \rho^{2}}\right] d v= \\
& =c_{p}^{i d}(T)-r+\frac{6 \rho C_{0}}{T^{3}}- \\
& -\frac{3 c \rho^{2}}{T^{3}}\left[\frac{2}{\gamma \rho^{2}}\left(1-e^{-\gamma \rho^{2}}\right)-e^{-\gamma \rho^{2}}\right] .
\end{aligned}
$$

To illustrate the applicability of the above equations, we show (Figure 2) calculated course of he isochoric heat capacity on temperature for $\mathrm{H}_{2} \mathrm{O}$ for volumes (top to bottom): $0.1 \mathrm{~m}^{3} / \mathrm{kg}, 0.08 \mathrm{~m}^{3} / \mathrm{kg}, 0.06 \mathrm{~m}^{3} / \mathrm{kg}, 0.04 \mathrm{~m}^{3} / \mathrm{kg}$ and $0.02 \mathrm{~m}^{3} / \mathrm{kg}$. All volumes were chosen so as to meet the condition $\rho_{r}<1$. As in the previous case, the experimentally determined course [7] is also plotted (squares points) and the limit curve is indicated in the diagram, too. Again, it is a nice match in locations distant from the limit boundary curve.

\section{Energy values}

An important variable in the calculation of the processes taking place in technical equipment is the enthalpy. Because we are working with BWR equation, it is with equation of the physical type, we will try to derive a dependence of the enthalpy on the temperature and volume. As a basis we assume the knowledge of the thermal equation of state BWR (1) and dependence of isobaric heat capacity in an idealized state gas on the temperature (8).

The full differential of enthalpy we can write the usual way as

$$
d h(T, p)=\left(\frac{\partial h}{\partial T}\right)_{p} d T+\left(\frac{\partial h}{\partial p}\right)_{T} d p .
$$

The partial derivative of enthalpy with temperature is the defining relation for the isobaric specific heat capacity (5). The partial derivative of enthalpy according to the pressure can be obtained by differentianting of the Gibbs equation $d h=T d s+v d p$

$\left(\frac{\partial h}{\partial p}\right)_{T}=T\left(\frac{\partial s}{\partial p}\right)_{T}+v$

and using Maxwell's equation $\left(\frac{\partial v}{\partial T}\right)_{p}=-\left(\frac{\partial s}{\partial p}\right)_{T}$

$\left(\frac{\partial h}{\partial p}\right)_{T}=-T\left(\frac{\partial v}{\partial T}\right)_{p}+v$

Substituting into equation (17) we obtain

$d h(T, p)=c_{p}(T, p) d T-\left[T\left(\frac{\partial v}{\partial T}\right)_{p}-v\right] d p$.

The full differential of pressure may break down

$d p=\left(\frac{\partial p}{\partial T}\right)_{V} d T+\left(\frac{\partial p}{\partial v}\right)_{T} d v$

We used further the relationship for the difference of the basic specific heat capacities

$c_{p}-c_{V}=T\left(\frac{\partial v}{\partial T}\right)_{p}\left(\frac{\partial p}{\partial T}\right)_{V}$

and after substituting (21) and (22) to (20) and adjustments we get the full differential enthalpy as a function of temperature and volume 
$d h(T, v)=c_{V} d T+v\left(\frac{\partial p}{\partial T}\right)_{V} d T+$

$+v\left(\frac{\partial p}{\partial v}\right)_{T} d v+T\left(\frac{\partial p}{\partial T}\right)_{V} d v$

Partial derivatives $\left(\frac{\partial p}{\partial v}\right)_{T}$ and $\left(\frac{\partial p}{\partial T}\right)_{V}$ it is possible to obtain from the BWR equation. The derivation $\left(\frac{\partial p}{\partial T}\right)_{V}$ was derived previously (13),

$$
\begin{aligned}
& \left(\frac{\partial p}{\partial v}\right)_{T}=-T \rho^{2} r-2 T \rho^{3} r B_{0}-3 T \rho^{4} r b+ \\
& +2 A_{0} \rho^{3}+3 a \rho^{4}-6 a \alpha \rho^{7}+\frac{2 \rho^{3} C_{0}}{T^{2}}+\left[-3 c \rho^{4}-\right. \\
& \left.-5 c \gamma \rho^{6}+\left(c \rho^{3}+\gamma c \rho^{5}\right) 2 \gamma \rho^{3}\right] \frac{e^{-\gamma \rho^{2}}}{T^{2}} .
\end{aligned}
$$

The dependence of enthalpy of the temperature and volume is obtained by integration the relation (23) between "known" and the current state over the volume. As in the case of specific heat capacity, it is chosen as the "known" state the idealized state $(v \rightarrow \infty)$ and at a temperature at which we know the value of the enthalpy $\left(T_{0}\right)$ :

$$
\begin{aligned}
& h(T, v)=h_{T_{0}}^{\infty}+\int_{T_{0}}^{T}\left[c_{V}^{i d}(T)+v^{i d}\left(\frac{\partial p}{\partial T}\right)_{V}^{i d}\right] d T+ \\
& +\int_{\infty}^{v}\left[v\left(\frac{\partial p}{\partial v}\right)_{T}+T\left(\frac{\partial p}{\partial T}\right)_{V}\right] d v .
\end{aligned}
$$

Substituting the partial derivatives (13) and (25), using the formula for the temperature dependence of the specific heat capacity (8), using the Mayer equation and by modifications we obtain [8]:

$$
\begin{aligned}
& h(T, v)=h_{T_{0}}^{\infty}+A\left(T-T_{0}\right)+\frac{B}{2}\left(T^{2}-T_{0}^{2}\right)+\frac{C}{3}\left(T^{3}-T_{0}^{3}\right)+ \\
& +\frac{D}{4}\left(T^{4}-T_{0}^{4}\right)+\rho\left[r T B_{0}-2 A_{0}-\frac{4 C_{0}}{T^{2}}\right]+ \\
& +\frac{\rho^{2}}{2}[2 r T b-3 a]+\frac{6 a \alpha \rho^{5}}{5}+ \\
& +\frac{c \rho^{2}}{T^{2}}\left[\frac{3}{\gamma \rho^{2}}\left(1-e^{-\gamma \rho^{2}}\right)-\frac{1}{2} e^{-\gamma \rho^{2}}+\gamma \rho^{2} e^{-\gamma \rho^{2}}\right] .
\end{aligned}
$$

To illustrate the applicability of the above equations, there are (on Figure 3) in $p-h$ diagram (density enthalpy diagram) plotted isotherms (top to bottom): $500^{\circ} \mathrm{C}, 300^{\circ} \mathrm{C}$ (in $p-v$ diagram was plotted the critical isotherm), $180^{\circ} \mathrm{C}$ and $100^{\circ} \mathrm{C}$. They are computed due to BWR equation of state. Dashed lines always show the actual course of the isotherm [7]. The diagram also plotted limit curve, too. Again, it is a nice match in locations distant from the limit boundary curve.

\section{Conclusions}

The energy values (the isochoric heat capacity and enthalpy) was obtained from BWR equation and from the polynomial dependence of isobaric heat capacity on the temperature of the gas in an idealized state. In the area of the compliance of the $p-v-T$ values obtained from BWR equation with experimental data on temperature, the obtained energy values and experimental data shows a very nice compliance, too. The procedure could therefore be used for obtaining such properties for example for hydrocarbons, for which the BWR equation gives very precise match with empirically measured data.

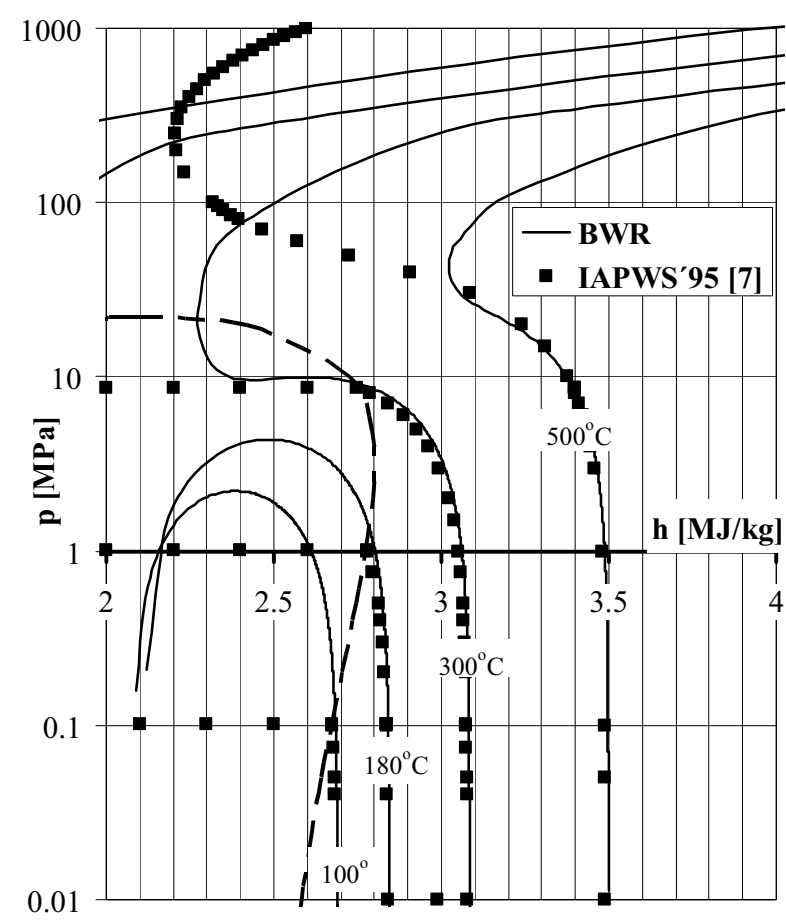

Figure 3. Comparison of isotherms of real substance according BWR equation and according IAPWS'95 data in the $p-h$ diagram (from below upwards: $100^{\circ} \mathrm{C}, 180^{\circ} \mathrm{C}, 300^{\circ} \mathrm{C}, 500^{\circ} \mathrm{C}$ ).

\section{References}

1. M. Benedict, G. Webb, L. C. Rubin, Journal of Chemical Physics 10 (12): 747-758 (1942)

2. M. Benedict, G. Webb, L. C. Rubin, Chemical Engineering Progress (CEP) 47 (8): 419-422 (1951)

3. J. Novák, Termodynamické vlastnosti plynů, (2007)

4. K. E. Starling, Fluid Properties for Light Petroleum Systems, (1973)

5. R. C. Reid, J. M. Prausnitz, B. E. Poling, The Properties of Gases \& Liquids (4th ed.) (1987)

6. B. A. Younglove, J. F. Ely, Journal of Physical and Chemical Reference Data 16 (4): 577 (1987)

7. O. Šifner, J. Klomfar, Mezinárodni standardy termofyzikálních vlastností vody a vodní páry, (1996)

8. I. Středa, Stavová rovnice BWR a termodynamické vlastnosti relných plynů a jejich směsí, (1987)

\section{Acknowledgments}

We gratefully acknowledge the support of the TUL Project SGS 21000. 